\section{Comment on 'Diagnostic delay in patients with rheumatoid arthritis, psoriatic arthritis and ankylosing spondylitis: results from the Danish nationwide DANBIO registry'}

Sørensen and Hetland state in their article ${ }^{1}$ and in their reply to a comment by Sykes et $a l^{2}$ a dramatic decrease of the delay in diagnosis for patients with ankylosing spondylitis since the year 2000. The results of their study can be summarised in the following way:

- For patients with a disease onset 10 years ago and a diagnosis made in the following 10 years, the delay in diagnosis was $0-10$ years, average 5 years.

- For patients with a disease onset 6 years ago and a diagnosis made in the following 6 years, the delay in diagnosis was $0-6$ years, average 3 years.

- And for patients with a disease onset 2 years ago and a diagnosis made in recent 2 years, the delay in diagnosis was $0-2$ years, average 1 year.

The authors neglected in their analysis and interpretation all the patients with recent symptom onset who were not yet diagnosed and are therefore not part of their database. Additional diagnoses have to be expected mainly for patients with recent disease onset, and the average delay in diagnosis found in the DANBIO register seems to be a realistic approximation only for former disease-onset decades, that is, for patients with symptom onset 20-40 years ago (see figure 1 for further illustration).

In 1989 Fries $\mathrm{et}^{\mathrm{al}} \mathrm{l}^{3}$ had already pointed out this fallacy in a similar study and referred to it as 'right censoring'. 'Right censoring' in its stricter sense, however, refers to a bias that is observed in survival studies which start with a population at risk and follow-up this population prospectively to a certain time point. Since Sørensen and Hetland ${ }^{1}$ did not follow-up such a population prospectively, we prefer not to speak here of right censoring in the original meaning but rather of an incorrect ana-

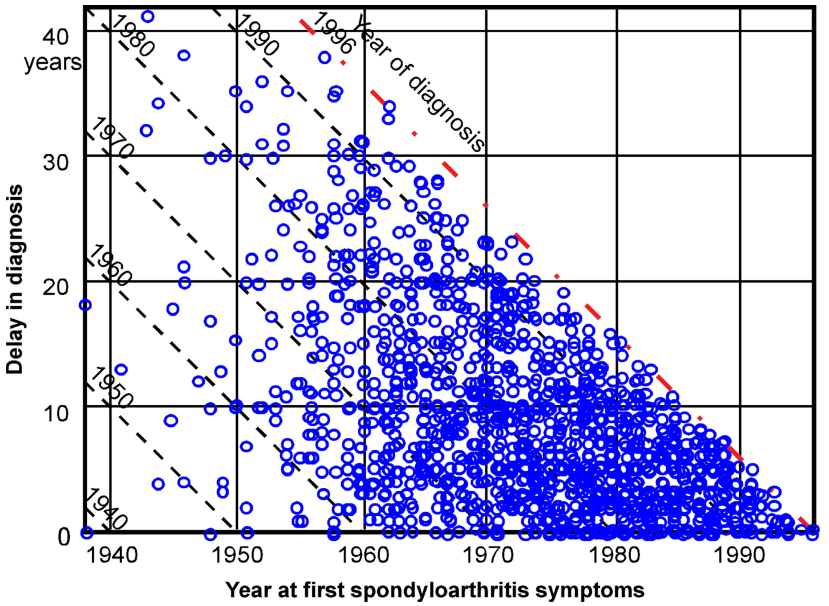

Figure 1 Distribution of the delay in diagnosis by the date of disease onset (first symptoms), as found in a survey of 1996 with 1380 patients with ankylosing spondylitis responding, and biasing limitation (red dash-dotted line) due to missing observations (diagnoses to be expected in the future). lysis and incorrect data interpretation that led to the fallacious results.

Sørensen and Hetland quote a publication by Salvadorini et $a l^{4}$ as having found similar results. However, the same fallacy occurred when Salvadorini et al interpreted their data as has already been pointed out in a comment ${ }^{5}$ to their publication.

Sykes et $a l^{2}$ already mentioned in their comment to the publication by Sørensen and Hetland ${ }^{1}$ the mistake of not accounting for missing observations (further diagnoses expected in the future), yet this important aspect seemed to be fully ignored by the authors in their reply.

In summary, the conclusions drawn by Sørensen and Hetland ${ }^{1}$ from their data analysis are not justified, and the study does not support a reduction in diagnostic delay. This does not exclude the possibility that the delay of time to diagnosis may indeed have been reduced between 2000 and 2011 as a result of modern imaging, new approaches to diagnosis, and more awareness in general. ${ }^{6}$ However, in order to demonstrate this reduction reliably, we need another 20 years passing by.

\section{Ernst Feldtkeller, ${ }^{1}$ Martin Rudwaleit ${ }^{2}$}

${ }^{1}$ Deutsche Vereinigung Morbus Bechterew, München, Germany

${ }^{2}$ Endokrinologikum Berlin, and Charité University Medicine, Berlin, Germany

Correspondence to Professor Ernst Feldtkeller, Deutsche Vereinigung Morbus Bechterew, Michaeliburgstr. 15, München D-81671, Germany;

e.feldtkeller@t-online.de

\section{Competing interests None.}

Provenance and peer review Not commissioned; externally peer reviewed.

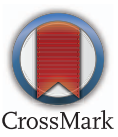

To cite Feldtkeller E, Rudwaleit M. Ann Rheum Dis 2014;73:e77.

Received 20 June 2014

Revised 27 July 2014

Accepted 12 September 2014

Published Online First 24 September 2014

\section{SLinked}

- http://dx.doi.org/10.1136/annrheumdis-2014-206612

Ann Rheum Dis 2014;73:e77. doi:10.1136/annrheumdis-2014-206126

\section{REFERENCES}

1 Sørensen J, Hetland ML; on behalf of all departments of rheumatology in Denmark. Diagnostic delay in patients with rheumatoid arthritis, psoriatic arthritis and ankylosing spondylitis: results from the Danish nationwide DANBIO registry. Ann Rheum Dis. Published Online First: 17 February 2014. doi:10.1136/ annrheumdis-2013-204867

2 Sykes M, Doll H, Gaffney K: Comment on: 'Diagnostic delay in patients with rheumatoid arthritis, psoriatic arthritis and ankylosing spondylitis: results from the Danish nationwide DANBIO registry' by Sørensen et al. Ann Rheum Dis 2014;73:e44 Reply published in Ann Rheum Dis 2014;73:7 e45.

3 Fries JF, Singh G, Bloch DA, et al. The natural history of ankylosing spondylitis: is the disease really changing? I Rheumatol 1989;16:860-3.

4 Salvadorini G, Bandinelli F, Delle Sedie A, et al. Ankylosing spondylitis: how diagnostic and therapeutic delay have changed over the last six decades. Clin Exp Rheumatol 2012;30:561-5.

5 Feldtkeller E, Zeller A, Rudwaleit M. Comment on 'Ankylosing spondylitis: how diagnostic and therapeutic delay have changed over the last six decades'. Clin Exp Rheumatol 2013;31:992.

6 Rudwaleit M, van der Heijde D, Khan MA, et al. How to diagnose axial spondyloarthritis early? Ann Rheum Dis 2004;61:535-43. 